\title{
Metodologias ativas: um estudo de caso do fenômeno aprender
}

\author{
Cláudio Boghi* \\ Dorlivete Moreira Shitsuka** \\ Ricardo Shitsuka***
}

\begin{abstract}
Resumo
Atualmente, muitos estudantes sentem medo em relação ao futuro incerto no que diz respeito às profissões que escolheram em relação ao futuro do emprego. Acredita-se que por meio do conhecimento seja possível superar os medos e adquirir confiança e autonomia. O objetivo deste trabalho é apresentar um estudo de caso de um professor de idioma estrangeiro que tem ministrado aulas durante anos, é bem quisto pelos seus alunos e aprende ativamente a cada aula. Realiza-se uma pesquisa qualitativa do tipo estudo de caso. Este artigo contribui para a educação geral brasileira e mundial, mostrando que é possível aprender habilidades e competências mesmo dentro do país, sem nunca ter viajado para o exterior. Esse professor já foi várias vezes aprovado em exames internacionais tipo TOEFL, recebe telefonemas internacionais e acompanha pessoas de fora, que elogiam seu conhecimento e sotaque perfeito.
\end{abstract}

Palavras-chave: Ensino e Aprendizagem. Educação. Aprendizagem de Idiomas.

\section{Active methodology: a case study on the pheno- menon of learning}

\section{Abstract}

Many students today are frightened about the uncertain future of the professions they have chosen in relation to the future of employment. It is believed that through knowledge it is possible to overcome fears and gain confidence and autonomy. The purpose of this paper is to present a case

\footnotetext{
* Universidade Anhembi-Morumbi. Mestre em Administração de Empresas

Mestre em Tecnologia Nuclear pelo IPEN-USP,

**Claretiano e UNIFMU. Mestre em Ensino de Ciências,

*** Universidade Federal de Itajubá. Mestre em Engenharia. Doutor em Ensino.
} 
study of a foreign language teacher who has taught classes for years, is well liked by his students and actively learns each class. A qualitative research of the case study type is carried out. This work contributes to general Brazilian and world education showing that it is possible to learn skills and competences even within the country, without ever having traveled abroad. This teacher has passed several times in international TOEFL tests, receives international phone calls and accompanies outsiders who choose their knowledge and perfect accent.

Key-words: Teaching and Learning. Education. Language Learning.

\section{Metodologias ativas: um estudo de caso do fenômeno aprender}

\section{Resumen}

Actualmente, muchos estudiantes sienten miedo en el futuro incierto con respecto a las profesiones que han elegido en relación con el futuro del empleo. Se cree que por medio del conocimiento es posible superar los miedos y adquirir confianza y autonomía. El objetivo del presente trabajo es presentar un estudio de caso de un profesor de idioma extranjero que ha impartido clases durante años, es bien querido por sus alumnos y aprende activamente a cada clase. Se realiza una investigación cualitativa del tipo estudio de caso. Este trabajo contribuye a la educación general brasileña y mundial mostrando que es posible aprender habilidades y competencias incluso dentro del país, sin nunca haber viajado al exterior. Este profesor ha sido varias veces aprobado en exámenes internacionales tipo TOEFL, recibe llamadas internacionales y acompaña a personas de fuera que elegían su conocimiento y acento perfecto.

Palabras clave: Enseñanza y Aprendizaje. Educación. Aprendizaje de Idiomas.

\section{Introdução}

Atualmente, vivemos em uma época com muita informação: as pessoas se comunicam por meio de redes sociais, celulares, assistem vídeos de web, e estudam em cursos a distância. Com tanta informação, que muitas vezes não é entendida e assimilada, muitos jovens tornam-se inseguros e também percebem a insegurança dos pais diante das mudanças. Como eles não sabem como resolver os 
problemas dos tempos atuais, muitas vezes passam a ter conflitos e a fornecer respostas ásperas para com pessoas que não têm culpa em relação às mudanças da sociedade. $\mathrm{O}$ quadro revela a perda de valores pelo jovem e o distanciamento dele em relação às outras pessoas e/ou aos mais velhos. A educação para a cidadania e o respeito às diferenças poderiam contribuir para diminuir as distâncias, no entanto, estas nem sempre conseguem acompanhar a velocidade dos jovens e quando é centrada em valores antigos nos quais os professores eram detentores do saber, pode ocorrer grande abismo entre professores e alunos. Uma das possibilidades é aquela na qual o professor é de fato uma pessoa com muito saber, dinâmica e bem-sucedida nos padrões atuais para o jovem se espelhar e isso nem sempre ocorre, além desse tipo de educação não possibilitar o desenvolvimento de habilidades e competências no estudante.

O objetivo deste trabalho é apresentar um estudo de caso do aumento gradativo de responsabilidade do aluno que acabou tendo que lecionar, passando de uma condição passiva para outra ativa, verificando-se a ocorrência da mudança comportamental associada ao aprendizado. Nas linhas seguintes, exibem-se em ordem e sequência os itens:

1. As metodologias antigas nas escolas.

2. As metodologias ativas e as mudanças na forma de ensinar e aprender.

3. Método da pesquisa por meio do estudo de caso.

4. O caso e comentários.

5. Nos itens finais, abordam-se as considerações finais e as referências dos autores citados no trabalho.

\section{As metodologias antigas nas escolas}

O modelo das aulas com expositivas vem desde os tempos modernos, quando surgiram as escolas. Nesse modelo, só o professor falava, era o detentor do saber, a autoridade na classe, e detentor do poder absoluto e inquestionável. Para Trindade e Meneses (2009), em relação às ideias educacionais dos tempos modernos, 
essas se iniciam pela Renascença, período em que se elabora o ideal pedagógico vivido pela França, desde o século XVI até o fim do século XVIII, na formação do espírito clássico. Tal modelo foi considerado como sendo o correto durante séculos e ainda é praticado em muitas escolas e instituições de ensino superior. Atualmente, ainda existem disciplinas e cursos na educação superior, nos quais as aulas são centradas no professor que é detentor de grande saber. Um exemplo disso ocorre na Medicina como consideram De Deus et al. (2014) que investigaram algumas disciplinas e concluíram que, apesar de os estudantes apreciarem as aulas centradas no professor, era preciso modificar essa prática, uma vez que o aprendizado acontece no aluno.

Freire (2013a) argumenta que aluno algum é uma tábua rasa, sem qualquer saber e que o tipo de educação na qual só o professor é o detentor do saber é conhecido como sendo a educação bancária. Nesse modelo, o professor pode ser considerado como possuindo uma mangueira da qual jorra a água que seria semelhante ao saber e esse professor encheria os potes vazios que seriam os estudantes. O próprio termo aluno vem da época antiga e é considerado como sendo ao pé da letra, possivelmente vem do prefixo de negação grego "a", com a palavra latina para luz que é "luminis". Nesse sentido, pode-se considerar que a palavra aluno teria um sentido original de uma pessoa "sem luz". Essas colocações, no entanto, não correspondem à realidade: as pessoas têm algum conhecimento prévio do lar, do meio, dos amigos, das experiências pelas quais já passaram e, dessa forma, não são potes vazios, como considera Freire (2013) e se torna importante refletir sobre esse importante aspecto educacional.

Para Moreira (2010), se quisermos melhorar o aprendizado, é preciso abandonar esse modelo tradicional e partir para outros nos quais possamos formar estudantes com autonomia e seres pensantes. Os alunos têm que ser desafiados, questionados, e permitir que eles falem, busquem soluções e construam o saber de modo ativo e esse modo de trabalho vai de encontro, em outras palavras, 
é contrário ao modelo tradicional no qual o professor é o centro das atenções nos processos de ensino e de aprendizado. É preciso um conjunto de ações que vão ao encontro dessa forma de atuar docente e discente. As metodologias ativas parecem trazer algumas mudanças na forma de ensinar e aprender.

\section{As metodologias ativas e as mudanças na for- ma de ensinar e aprender}

Metodologias ativas não são coisas novas, mas já eram praticadas de muitas formas, fazendo os alunos se tornarem autônomos e responsáveis pelo seu aprendizado. Moran (2015) considera que quando queremos ter alunos proativos, precisamos utilizar metodologias nas quais eles se envolvam em atividades gradativamente com complexidade crescente, nas quais tenham que tomar decisões e avaliar os resultados, com apoio de materiais relevantes. Para que os estudantes sejam compromissados e envolvidos, é preciso criar condições favoráveis para que isso ocorra e esse é o caso do emprego das metodologias ativas. Para Sobral e Campos (2009), tais metodologias são concepções educativas que incentivam a participação dos estudantes de modo responsável e compromissado com o processo educacional. Tudo passa pelas questões dos incentivos. Segundo Campos (2008), estes são "forças" externas às pessoas que podem provocar o surgimento de "forças" internas às pessoas, denominadas genericamente de motivação.

Dewey (1959) considera importante que os estudantes aprendam a buscar o saber de forma autônoma por meio de projetos e descobertas. Em sua concepção, a sala de aula era um laboratório e apostava no ensino de modo prático. Mesmo não tendo essa terminologia, esse pesquisador já trabalhava com metodologias ativas. Freire (2013b) aponta no mesmo sentido da necessidade de trabalhar a autonomia do estudante para que ocorra seu desenvolvimento com autoconfiança. Ausubel, Novak e Hanesian (1980) consideram que, à medida que um estudante consegue aprender de modo autônomo por meio de descoberta, ele aprende significativa- 
mente. $\mathrm{O}$ aprendizado significativo é aquele que é duradouro e útil para o ser aprendente. Torna-se interessante que esse ser seja um ser ativo nesse aprendizado e para que isso ocorra é preciso que existam metodologias nas escolas. Os autores ibid., no entanto, não explicam como surgem a motivação e consideram que esta já tem que estar presente no aluno.

As chamadas metodologias ativas se constituem em formas interessantes de ação para que ocorra a motivação para o aprendizado e, por conseguinte, o desenvolvimento de habilidades, competências e o saber nos estudantes. Tais metodologias incluem as atividades, desde as mais simples que fazem que o estudante seja colocado como responsável pela sua realização, até as mais complexas. Berbel (2011), Rocha (2012), Barbosa e Moura (2013), Gouvea et al. (2015a), Gouvea et al. (2015b) e Gouvea et al. 2016) consideram que entre as formas mais simples estão a busca de informações, a elaboração textual, a participação em redes sociais, a elaboração de vídeos, trabalho colaborativo e outras semelhantes que já fazem que ocorra um trabalho ativo e para isso é importante que o aluno assuma sua parte no processo educacional.

Outros modos mais avançados incluem a pedagogia por projetos e por meio da resolução de problemas. Torna-se importante fazer o aluno se sentir envolvido, querer buscar a resolução do problema, se responsabilizar, pensar e, enfim, aprender ativamente. Observa-se que o fato mais simples e importante é fazer o aluno se envolver ativamente, uma vez que os professores sabem que é nele que vai ocorrer o aprendizado. Para que ocorra o envolvimento, é necessário que exista uma motivação.

\section{Metodologia}

Pesquisa é uma forma sistemática e metódica que visa obter saberes. Demo (2011), Batista; Campos, 2013, Yin, 2015 consideram que ela pode ser qualitativa quando se preocupa com as opiniões dos entrevistados em pesquisas sociais e busca interpretar fenômenos, ou então, quantitativa quando está preocupada com 
números. Severino (2016) considera que ela forma um tripé, necessário à formação do estudante universitário, que é composto por ensino, pesquisa e extensão. Neste trabalho, realiza-se uma pesquisa qualitativa do estudo de caso que é um tipo de pesquisa na qual se estuda um fenômeno único, detalhadamente e numa linguagem simples (LUDKE; ANDRÉ, 2013).

O fenômeno em estudo é a mudança de comportamento por meio da metodologia ativa que ocorre num jovem que se torna professor de idiomas. O motivo da escolha do jovem do caso ocorreu pelo fato desse professor ser muito elogiado tanto pelos seus alunos como também pelas pessoas estrangeiras que vêm ao país e são acompanhadas e o consideram como tendo excelente conhecimento, pronúncia e educação apesar de ele não ter viajado para o exterior nem residido em outro país. $\mathrm{Na}$ observação das declarações, utiliza-se a análise de conteúdo linha francesa. Para Pêcheux (2011), o entendimento de um enunciado pode ser realizado por meio do estudo de fatores externos que podem ajudar a fazer sentido necessário à compreensão da fenomenologia. Por questões éticas e em respeito ao pedido do protagonista, evitou-se citar nomes e localidades, procurando-se concentrar no fenômeno, sua descrição e interpretação.

\section{O caso e comentários}

Nosso foco está em um professor que, desde jovem, aos 14 anos de idade, estudava numa escola de idiomas que frequentava regularmente e o fez até os 17 anos de idade, quando concluiu os estágios. O senso comum diz que o jovem aprende com mais facilidade por não ter ranços e preconceitos que ocorrem com as pessoas de mais idade. $\mathrm{Na}$ época, como frequentava regularmente o curso, passou a ajudar os professores e o pessoal da secretaria e, logo, passado o período militar, por dispensa, foi contratado para trabalhar na secretaria do curso. Como já havia concluído os módulos e estudado durante anos, já possuía uma pronúncia boa e tinha facilidade em assistir vídeos estrangeiros na língua original. 
Em algumas oportunidades, nas quais algum professor de idiomas faltava, ele entrava em sala e logo, devido à facilidade que se comunicava e lidava com os alunos, foi contratado como professor na escola de idiomas. A partir da mudança na qual agora ele era o professor, muito embora não possuísse uma formação superior em Letras, ele era "de facto" um professor em sala de aula e, a partir disso, assume uma postura diferente, voltada para entender mais os alunos, de forma empática e, desse modo, passa a ser admirado e respeitado por todos uma vez que a empatia é uma atitude que cativa as pessoas. Como prossegue diariamente tentando melhorar seu repertório, seu vocabulário se enriquece a cada dia, torna-se verdadeiramente aficionado pelo seu trabalho como professor e após alguns anos passa a lecionar para outras escolas e torna-se bem-sucedido. Por meio do seu ganho com seu salário, consegue manter-se, pagar a faculdade, e se orgulha em ajudar em várias despesas dos pais. Atualmente, conta com cerca de 25 anos e em 2017, ao ser entrevistado apresentou as seguintes respostas:

Qual a sua idade atual e com quantos anos começou a trabalhar? Seu trabalho foi na área na qual você estudava? Você gosta ou gostava do que faz ou passou a gostar posteriormente?

Resposta: Atualmente, em 2016, possuo 25 anos de idade e comecei a trabalhar quando estava com 18 anos de idade. O trabalho inicial foi na área que eu estudava já fazia alguns anos que era trabalhar com idioma estrangeiro. Eu gostava de ver os professores ensinando e en queria ser professor por isso en já gostava deste tipo de trabalho.

\section{Análise:}

O trabalho é uma forma de atribuir responsabilidade ao jovem. Por meio do trabalho, muitas pessoas se aperfeiçoam, aprendem a viver em sociedade, a respeitar regras e a conviver com o próximo. No caso do rapaz em foco, ele já gostava desse tipo de trabalho antes mesmo de exercê-lo e, por isso, segundo Ausubel, Novak e Hanesian (1980) ele já se encontrava motivado para exercer a profissão e continuar aprendendo nela. A motivação é uma força interna que surge como resposta a incentivos externos como 
considera Campos (2008). Um dos fatores externos que podem ter contribuído para o surgimento da motivação foi o fato de que tendo estudado, ele falava e os outros entendiam e com isso aumentava seu interesse pelo aprendizado. De modo semelhante, ao assistir os vídeos, como ele já os entendia, aumentava sua motivação em prosseguir. $\mathrm{O}$ aluno motivado aprende mais e continua avançando na sua escolha, sua carreira ou seu caminho.

Quando você começou a trabalhar, você e as pessoas do seu convívio sentiram alguma mudança?

Resposta: eu me senti mais responsável, passei a conversar mais e a respeitar mais as pessoas. Minha mãe afirma que eu costumava reclamar de tudo, dizia que a comida estava ruim, estavam me acordando muito cedo, não gostava que me perguntassem sobre a minha vida. Após começar a trabalhar, todos afirmam que fiquei mais sociável, atencioso, educado e costumo sorrir mais. Sinto que o fato de ter que ensinar me fez perceber que as pessoas precisavam de mim. Era preciso que eu entendesse elas e não o contrário como eu tinha vivido anteriormente. Agora eu era o professor e todos confiavam em mim.

\section{Análise:}

Verifica-se pela fala do jovem que houve uma mudança comportamental quando ele passa a trabalhar como professor. Segundo Freire (2013), ensinamos e aprendemos, no sentido de que o "ensinar" é uma metodologia ativa que obriga o estudante buscar mais saber para poder lecionar como professor. Há um divisor de águas no sentido da responsabilidade. O professor tem que se preocupar com o aprendizado dos seus alunos e passa então a valorizar mais a figura do próximo.

O jovem passa a perceber que o próximo é um ser diferente com necessidades, dificuldades e que para que aprenda é preciso saber lidar com as necessidades desse próximo. Ele passa então a prestar mais atenção às pessoas e se torna mais sociável e a dialogia o torna mais afetivo. Segundo Wallon (2008), um dos componentes importantes para ocorrer o aprendizado humano é a afetividade. Nesse ponto, sua mãe, conforme sua declaração, afirma que ele mudou o comportamento e se tornou um "filho melhor". A mudança de comportamento veio pelo aprendizado. Educação é mudança de 
comportamento. Essa mudança faz que o rapaz estude mais, procure concentrar-se em conhecer as pessoas e atendê-las, melhora seu aspecto de cidadania. Sua percepção passa a considerar mais o próximo que está à sua volta. O fato de ter que exercer o papel de professor, com autonomia e responsabilidade, faz que ele passe por um aprendizado ativo. A metodologia ativa ocorre de modo semelhante ao que consideram Berbel (2011), Rocha (2012), Barbosa e Moura (2013), Gouvea et al. (2015a), Gouvea et al. (2015b), Gouvea et al. (2016) e Boghi et al. (2016) que consideram que é importante que o aluno assuma sua parte no processo educacional em curso e tudo leva crer que é o fenômeno que ocorre quando o aluno muda sua condição para professor.

O que você considera que mudou com a prática como professor em relação à sua condição anterior?

Resposta: Quando eu comecei a lecionar, senti o peso da responsabilidade. Antes eu gostava de falar e pensar em outros idiomas, mas quando passei a fazer profissionalmente, mudei minhas vestimentas, passei a prestar mais atenção às pessoas e passei a estudar mais, assistindo mais videos, e passei na primeira vez que fiz meu exame Toef. Acho que todo mundo que quer aprender mesmo precisa ter coragem de ensinar, se expor publicamente, se aperfeiçoar continuadamente e aprender de modo ativo. Estou muito feliz com o progresso que fiz:

\section{Análise:}

As palavras do jovem apontam no sentido da aprendizagem ativa e se pode inferir que o ensinar aprendendo também se constitui numa metodologia ativa de aprendizagem. Nesta, o professor é colocado numa situação social na qual ele tem que tomar a iniciativa, tem que conversar com a classe, incentivar os discentes, apresentar a matéria, mostrar exemplos, desenvolver formas de fazer seus estudantes aprenderem socialmente e, nesse processo, como consideram Freire (2013a) e Freire (2013b) ele também aprende. Esse fato pode ser comprovado pela afirmação do jovem professor que passou na sua primeira tentativa ao realizar o exame internacional do Toefl, que é um dos mais conceituados internacionalmente.

Em relação ao comportamento anterior ao seu trabalho como professor, verifica-se que ele superou muitos aspectos como 
é o caso típico do egoísmo e individualismo possuído por muitos jovens e que é característico dos tempos atuais pós-modernos. Passa a se preocupar mais com as outras pessoas, age com cidadania e procura incentivar que seus alunos ajam de forma semelhante. Para Gouvea et al. (2015a), Gouvea (2015b) e Gouvea (2016), por meio das metodologias ativas torna-se possível enfrentar as dificuldades trazidas pelos tempos pós-modernos como é o caso da individualidade dos jovens. O presente estudo contribui para a educação brasileira no sentido de mostrar que é possível ensinar aprendendo, e que ensinar se constitui numa metodologia ativa, que pode fazer um jovem mudar seu comportamento e passar a buscar o saber com autonomia, cidadania e respeito pelo próximo.

Sugere-se para estudos posteriores que se verifiquem formas de fazer que os estudantes dos diversos cursos de graduação também possam atuar ensinando de alguma forma a sociedade e, desse modo, contribuindo para o seu próprio aprendizado e esta pode ser uma maneira de melhorar a educação superior.

\section{Considerações finais}

Este trabalho apresentou o caso de um professor de idioma estrangeiro que tem ministrado aulas durante anos e é benquisto pelos seus alunos e aprende ativamente a cada aula.

Aprendizado envolve mudança comportamental e, no caso, o jovem ao passar de estudante para profissional do ensino, passa a se comportar de outra forma tanto na vestimenta, na questão da cidadania, quanto no trato com as pessoas como também no seu próprio engajamento com os estudos.

Desde os tempos de estudante, o jovem professor já estava motivado para seguir nessa área de atuação e na medida em que foram surgindo as oportunidades, ele as agarrou com vontade de vencer e se mostrou bem-sucedido.

Este estudo contribui para a educação nacional mostrando que é possível "ensinar aprendendo", em outras palavras, que ensinar se constitui numa metodologia ativa, que pode fazer que um 
jovem mude seu comportamento e passe a buscar o saber continuadamente, com autonomia, cidadania e respeito e consideração pelo próximo.

À medida que o jovem adquire responsabilidade, pode se tornar mais seguro de seu papel na sociedade e, dessa forma, esse jovem pode se aproximar dos mais velhos até para trocar ideais e buscar mais sabedoria e comportamento cidadão de modo a fazer frente aos tempos atuais de insegurança.

Como sugestão para estudos futuros, os autores consideram que é interessante que se encontrem formas de fazer que os estudantes dos diversos cursos de graduação também possam atuar ensinando de alguma forma a sociedade e, desse modo, contribuindo para o seu próprio aprendizado ativo.

\section{Referências}

AUSUBEL, D. P.; NOVAK, J. D.; HANESIAN. H. Psicologia educacional, 2. ed. Rio de Janeiro: Interamericana, 1980.

BARBOSA, E. F; MOURA, D. G. Metodologias ativas de aprendizagem na educação profissional e tecnológica. B. Tec. Senac, Rio de Janeiro, v. 39, n. 2, p. 48-67, mai./ago. 2013.

BERBEL, N. A. N. As metodologias ativas e a promoção da autonomia de estudantes. Semina: Ciências Sociais e Humanas, v. 32, n. 1, p. 25-40, 2011. Disponível em: < http://www.proiac.uff.br/sites/default/files/documentos/berbel_2011.pdf. >. Acesso em: 27 fev. 2016.

CAMPOS, D. M. S. Psicologia da aprendizagem, 37. ed. Petrópolis: Vozes, 2008.

De DEUS, J. M., et al. Aula Centrada no aluno versus aula Centrada no Professor. Desafios para mudança. Revista Brasileira de Educação Médica, v. 38, n. 4, p. 419-426, 2014.

DEWEY, J. Vida e Educação. São Paulo: Nacional, 1959.

FREIRE (a), P. Pedagogia do oprimido. São Paulo: Paz e Terra, 2013. 
FREIRE (b), P. Pedagogia da Autonomia. São Paulo: Paz e Terra, 2013.

GOUVEA (2015a), E. P. et al. Um trabalho de pesquisa-ação com uso de metodologia ativa no ensino de tecnologia de informação. REGS - Educação, Gestão e Sociedade: revista da Faculdade Eça de Queirós, ISSN 2179-9636, v. 5, n. 20, nov. 2015. Disponível em: <http://www.faceq.edu.br/regs/downloads/numero20/ 1-Um-trabalho-de-pesquisa-acao.pdf>. Acesso em: 6 abr. 2016.

GOUVEA (2015b), E. P. et al. Estudo de caso sobre o emprego de metodologia ativa no desenvolvimento de um sistemas de informação para web. RAFE - Revista Acadêmica da Faculdade Fernão Dias, ISSN 2358-9140, v. 2, n. 6, novembro de 2015. Disponível em: <http://www.faculdadefernaodias.edu.br/ rafe/>. Acesso em: 6 abr. 2016.

GOUVEA (2016), Eduardo P. et al. Metodologias ativas: uma experiência com mapas conceituais. REGS - Educação, Gestão e Sociedade: revista da Faculdade Eça de Queirós, ISSN 2179-9636, v. 6, n. 21, fev. 2016. Disponível em: <http://www.faceq.edu.br/regs/downloads/numero21/4-Metodologias-ativas. pdf $>$. Acesso em: 6 abr. 2016.

MORAN, J. M. Mudando a educação com metodologias ativas. In: Coleção Mídias Contemporâneas. Convergências Midiáticas, Educação e Cidadania: aproximações jovens. Vol. II. Carlos Alberto de Souza e Ofelia Elisa Torres Morales (Orgs.). PG: Foca Foto-PROEX/UEPG, 2015.

MOREIRA, M. A. Abandono da narrativa, ensino centrado no aluno e aprender a aprender criticamente. In: Conferência proferida no II Encontro Nacional de Ensino de Ciências da Saúde e do Ambiente, Niterói, RJ, 12 a 15 de maio de 2010 e no VI Encontro Internacional e III Encontro Nacional de Aprendizagem Significativa, São Paulo, SP, 26 a 30 de julho de 2010. Disponível em: <http:// www.if.ufrgs.br/ moreira/Abandonoport.pdf>. Acesso em: 18 abr. 2016.

PÊCHEUX. M. Análise do discurso. São Paulo: Cortez, 2011.

ROCHA, E. F. Metodologias Ativas: um desafio além das quatro paredes da sala de aula. In: Encontro Nacional de Professores em Educação a Distancia - ENPED 2012. Disponível em: < http://www.abed.org.br/arquivos/Metodologias_Ativas_ alem_da_sala_de_aula_Enilton_Rocha.pdf>. Acesso em: 28 fev. 2016.

SEVERINO, A. J. Metodologia do trabalho científico, 24. ed. São Paulo: Cortez, 2016. 
SOBRAL, F. R.; CAMPOS, C. J. G. Utilização de metodologia ativa no ensino e assistência de enfermagem na produção nacional: revisão integrativa. Rev Esc Enferm USP, v. 46, n. 1, p. 208-218, 2012. Disponível em: <www.ee.usp.br/reeusp/>. Acesso em: 28 fev. 2016.

TRINDADE, S. A.; MENEZES, I. R. A educação na modernidade e a modernização da escola no Brasil: século XIX e início do século XX. Revista HISTEDBR On-line, Campinas, n. 36, p. 124-135, dez. 2009 - ISSN: 1676-2584.

YIN, R. K. O estudo de caso. Porto Alegre: Bookman, 2015.

Submetido em: 27-3-2018

Aceito em: 3-4-2018 